\title{
Control of the System of Piezoelectric Actuator Devices for Precision Drive Systems
}

\author{
Stanislav Matveev \\ Vice-Rector for Scientific Work and Innovative Communication Technologies, \\ Faculty of Information and Control Systems, \\ Department of Control Systems and Computer Technology, \\ Baltic State Technical University "VOENMEH", \\ St. Petersburg, 190005, Russia. \\ Corresponding author: stas_matveev@mail.ru \\ Nikolai Yakovenko \\ Faculty of Information and Control Systems, \\ Department of Drive Systems, Mechatronics and Robotics, \\ Baltic State Technical University "VOENMEH", \\ St. Petersburg, 190005, Russia. \\ E-mail: yakovenko_ng@mail.ru

\section{Yuri Konoplev} \\ Faculty of Rocket and Space Technology, \\ Department of Control Processes, \\ Baltic State Technical University "VOENMEH", \\ St. Petersburg, 190005, Russia. \\ E-mail: urzig_eastwood@mail.ru

\section{Andrei Gorbunov} \\ Faculty of Information and Control Systems, \\ Department of Control Systems and Computer Technology, \\ Baltic State Technical University "VOENMEH", \\ St. Petersburg, 190005, Russia. \\ E-mail: anygos@yandex.ru
}

\author{
Alexander Shirshov \\ Faculty of Information and Control Systems, \\ Department of Control Systems and Computer Technology, \\ Baltic State Technical University "VOENMEH", \\ St. Petersburg, 190005, Russia. \\ E-mail: shaldmi@inbox.ru \\ Nikolay Didenko \\ Research Laboratory "System Dynamics", \\ Peter the Great St. Petersburg Polytechnic University, \\ St. Petersburg, 195251, Russia. \\ E-mail: didenko40@list.ru
}

(Received May 12, 2019; Accepted September 11, 2019) 
International Journal of Mathematical, Engineering and Management Sciences

Vol. 5, No. 2, 319-327, 2020

https://doi.org/10.33889/IJMEMS.2020.5.2.026

\section{Abstract}

In the work problems related to control of precision piezoelectric actuator devices, piezo actuators in particular, are discussed. Multichannel system of control of piezo actuators is presented. Possibility of using the said control system to control the shape of the space-based large transformed antenna is discussed.

Keywords- Precision actuator devices, Amplifier driver, Microcontroller, Control signal, Piezo actuator, Stroke length, PCB.

\section{Introduction}

Currently, technical requirements to the precision systems result in the need for search for new technical decisions that would correspond to the requirements at minimum financial expenditures and energy cost though meeting or exceeding its precursors in terms of functionality (Mitin and Krivushov, 2018).

One of such decisions is application of high-accuracy positioning piezo actuators operating based on the inverse piezoelectric effect, i.e. on the conversion of electric power into mechanical one (Kuptsov 2016; Vasil'ev et al., 2017; Choe et al., 2017; Vassiliev et al., 2017). Piezo actuators are structures consisting of several piezo elements, which allows enhancing their functional capabilities, improving travel range in particular (Heijer et al., 2014). Figure 1 gives the scheme of one of the possible piezo actuator version consisting of piezo elements multilayer package.

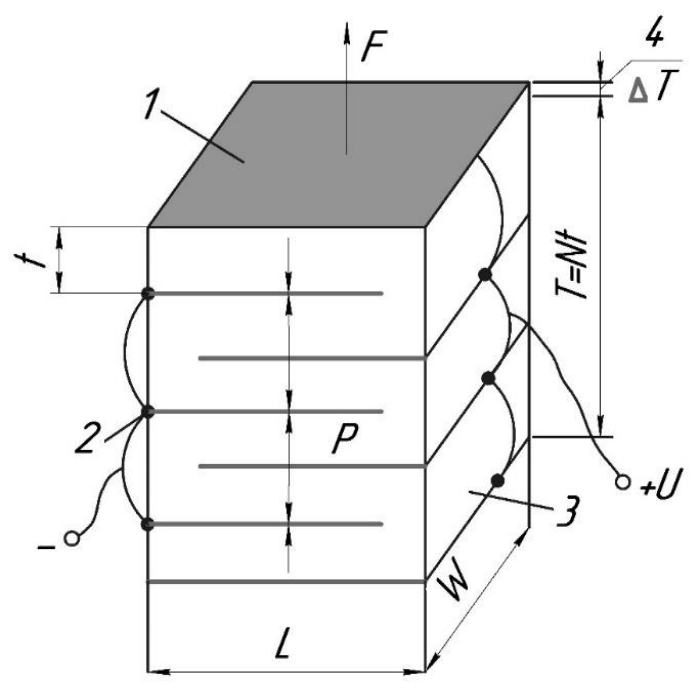

Figure 1. Scheme of piezo actuator consisting of piezo elements multilayer package: 1 - external electrode; 2 - internal electrodes; 3 - piezo material, 4 - piezo material expansion

At application of the external electric field with the difference of potentials coincident with the plate polarisation direction, piezo material expansion takes place over its thickness or along the polarisation axis. The stroke length of the said piezo actuators can be within the range of tens of nanometers through tens of micrometers, and the force' range can make several tens through hundreds of Newtons (Bardin and Vasil'ev, 2014; Halabi et al., 2018). 
International Journal of Mathematical, Engineering and Management Sciences

Vol. 5, No. 2, 319-327, 2020

https://doi.org/10.33889/IJMEMS.2020.5.2.026

Use of piezo actuators becomes of special importance in the development of spacecraft where actuation devices should feature rather small mass and size characteristics, possess substantial developed force and allow a separate control object included into the technical system performing precision movements (Matveev et al., 2018). For instance, to arrange the communication channel between the earth-based station and the spacecraft is necessary to accurately form the antenna pattern, since even its smallest deviations can result in substantial losses in signals reception or transmission (Frolov et al., 2018; Kiseleva et al., 2018; Medvedev et al., 2018; Yenuchenko, 2018). Accuracy of the above-mentioned antenna pattern forming can ensure getting the transformed antenna where control of the radio-reflective surface shape is ensured by changes in the cables' length (Zhengrong et al., 2014; Yiqun et al., 2016). Cables are positioned between the reflector' front and rear network (Yiqun et al., 2017).

\section{Linear Drive Based on the System of Piezo Actuators}

Systems consisting of two, three or more piezo actuators connected with each other can be of the utmost interest. The said approach to the problem allows performing movement at the required distance in one or several needed directions (Bardin and Vasil'ev, 2017; Osipov et al., 2018). Figure 2 shows general view of the developed piezoelectric linear drive intended for changing length of cords of the large-size transformed antenna' shape-forming structure.

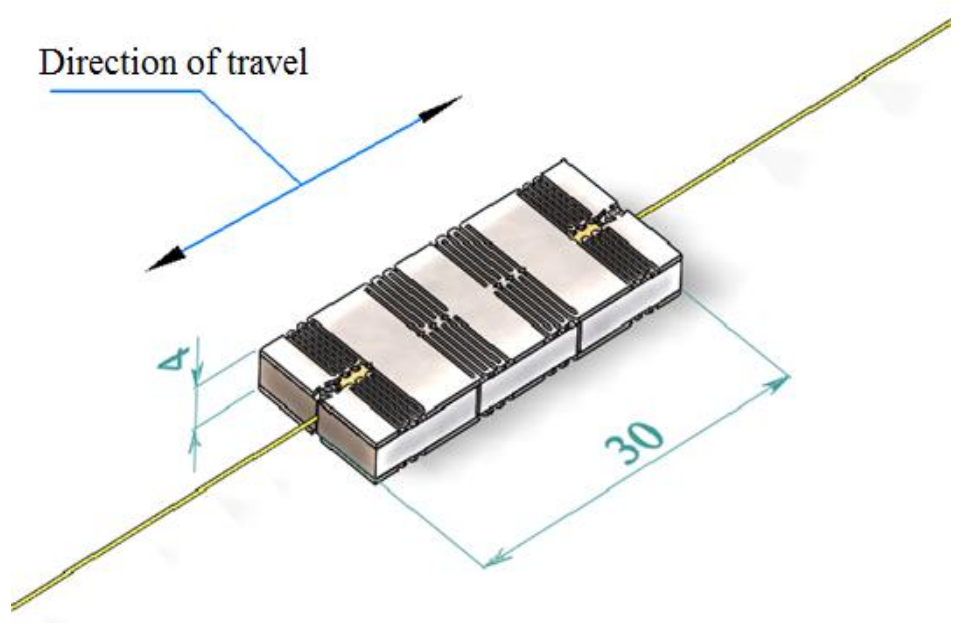

Figure 2. General view of the developed piezoelectric linear drive

The linear drive executes translational motion along the cable structure' cord (Kabanov et al., 2018). One of the cord's end is fixed to the drive body. The end passes through the pulley structure that is fixed on the shape of the frontal network at the base of the control point. At rest, the drive is in the closed loop state, which allows maintaining the pre-set position at power off.

In the developed piezoelectric linear drive system, control of piezo actuators' stroke value is assigned by pulse repetition frequency of the control signals from the microcontroller' outputs (Chi and Xu, 2014; Varlamov et al., 2018; Varlamov et al., 2019). Piezo actuators adjacent to the cable operate in synchronous manner and form a pair having the single control signal. The control 
algorithm is based on the phase difference between the channels where control signals of the end pairs of the drive' piezo actuators are in antiphase, while the control signal of the internal pair of the drive' piezo actuators has several microseconds propagation delay. Pulses duration is determined by electrical capacitance of the certain piezo actuator models. Figure 3 gives the control algorithm' general view.

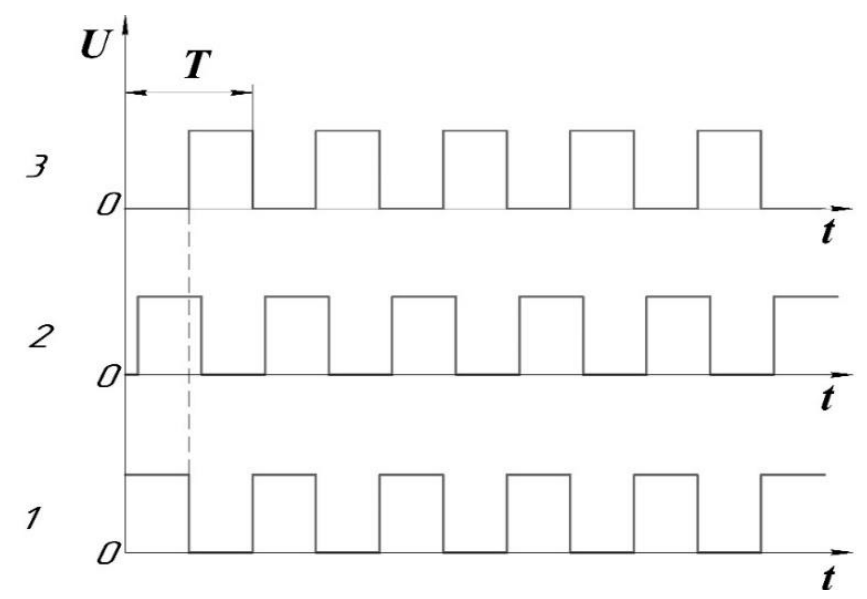

Figure 3. General view of the control algorithm

\section{Amplifier Driver for the Drive Based on the System of Piezo Actuators}

As a rule, piezo actuators feature high power supply voltage and low current consumption values. That is why the most relevant objective faced by the developers eager to integrate this type of actuators into the technical system being designed is development of the amplifier driver ensuring the required voltage and the stroke length control capability (Kabanov et al., 2018).

The amplifier driver developed and proposed for discussion allows converting input 2.7 V DC voltage into pulsating voltage with $160 \mathrm{~V}$ amplitude at the output. At the external microcontroller connection, 3 square waves are formed at the output ensuring the possibility of controlling the piezo actuators' stroke value. The amplifier device scheme includes DC-DC converter, H-bridge scheme, voltage multiplier, and power MOSFET-transistor switches. It should be noted that power MOSFET-transistor switches components are to be individually selected, i.e. for each specific piezo actuator model. For the converter' microcircuit, MC34063 universal microcircuit for typical pulse converters was selected. Step-down, step-up or inverting converters can be created based on the said microcircuit without using any external switching transistors. The MC34063 circuit' principal technical specifications are as follows:

- Wide range of input voltage values, from 3 to $40 \mathrm{~V}$;

- High output pulse current, up to $1.5 \mathrm{~A}$;

- Adjustable output voltage;

- Converter frequency up to $100 \mathrm{kHz}$.

Figure 4 demonstrates the microcircuit structure. 
International Journal of Mathematical, Engineering and Management Sciences

Vol. 5, No. 2, 319-327, 2020

https://doi.org/10.33889/IJMEMS.2020.5.2.026

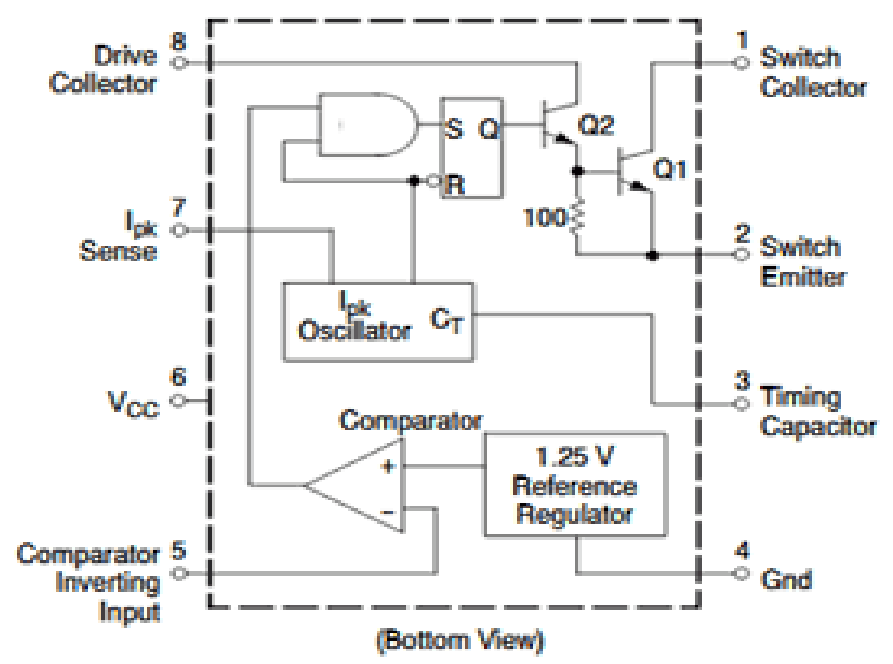

Figure 4. The microcircuit structure

Nominal values of the typical application circuit' components were computed considering the possibility of increasing the output voltage up to $40 \mathrm{~V}$ from the supply voltage of $2.7 \mathrm{~V}$;

$$
\begin{gathered}
V_{\text {out }}=1.25\left(1+\frac{R_{2}}{R_{1}}\right), \\
t_{\text {on }} / t_{\text {off }}=\frac{V_{\text {oUT }}+V_{F}-V_{I N(\min )}}{V_{I N(\min )}-V_{\text {sat }}}, \\
I_{P K(\text { swith })}=2 I_{\text {out (max) }}\left[\left(t_{\text {on }} / t_{\text {off }}\right)+1\right], \\
C_{o}=\frac{I_{\text {oUT }} t_{\text {on }}}{V_{\text {ripple }(p-p)}}, \\
L_{(\min )}=\frac{V_{I N(\min )}-V_{\text {sat }}}{I_{P K(\text { swith })}} t_{\text {on(min) }} .
\end{gathered}
$$

Here

$V_{s a t}$ - Saturation voltage of the output switch

$V_{f}$ - Forward voltage drop of the output rectifier

$V_{I N}$ - Nominal input voltage

$V_{\text {out }}-$ Desired output voltage

$I_{\text {out }}-$ Desired output current

$V_{\text {ripple }}$ - Desired peak to peak output ripple voltage. 
International Journal of Mathematical, Engineering and Management Sciences

Vol. 5, No. 2, 319-327, 2020

https://doi.org/10.33889/IJMEMS.2020.5.2.026

The developed driver advantages are as follows:

- Capability of the output power adjustment;

- The structure assignment to minimize the weight and size characteristics.

Capability of the output power adjustment is achieved by recomputation of the components of the typical application circuit nominal values and frequency of the MC34063 converter microcircuit, as well as by adding or decreasing voltage multiplier cascades. The said capability renders unique character to the developed concept of the amplifier driver' circuit making it the universal device for ensuring the required power and the required control of various piezoelectric actuator devices, piezo actuators in particular. The driver assignment to minimize the weight and size characteristics is ensured by the possibility of the PCB implementation on the smd components. Figure 5 demonstrates 3D model of the developed driver' PCB design.

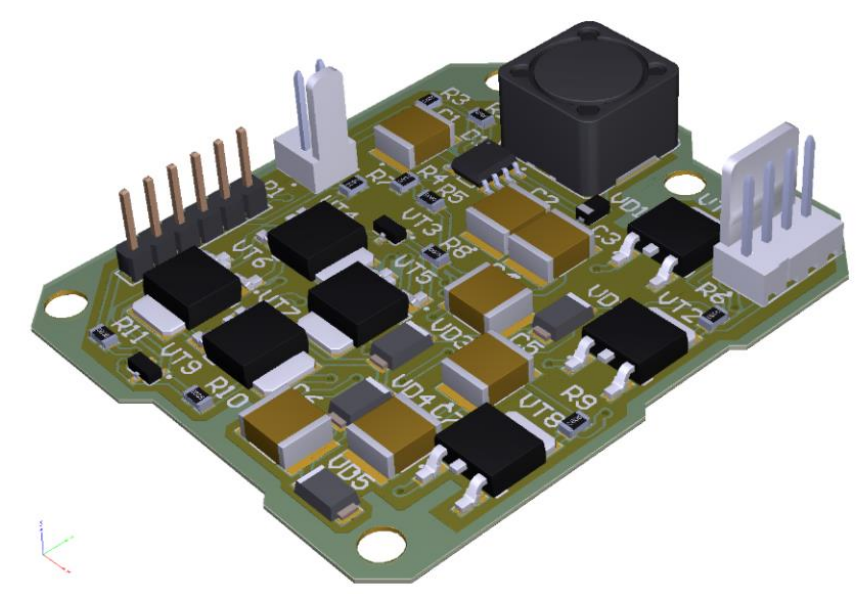

Figure 5. 3D model of the developed driver' PCB design

Topology of the PCB Top layer is presented in Figure 6.

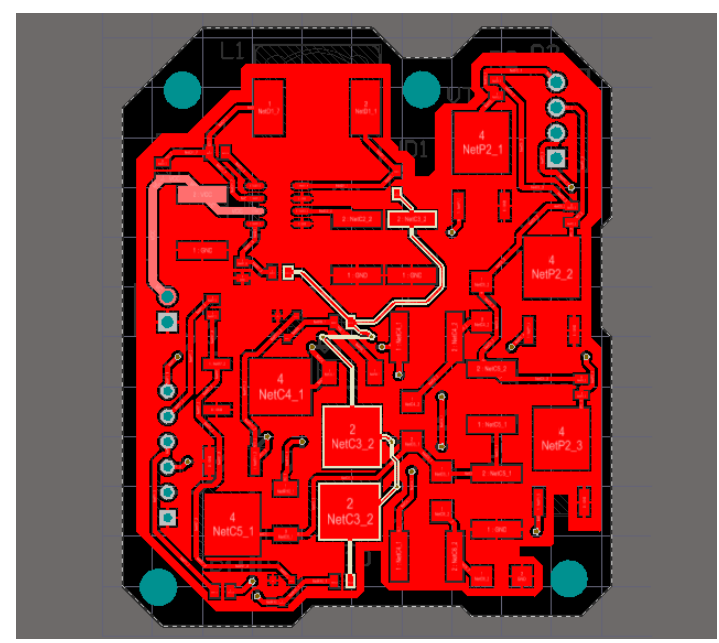

Figure 6. Topology of the PCB top layer 
International Journal of Mathematical, Engineering and Management Sciences

Vol. 5, No. 2, 319-327, 2020

https://doi.org/10.33889/IJMEMS.2020.5.2.026

Table 1 gives the principal technical specifications of the developed driver.

Table 1. The developed driver' principal technical specifications

\begin{tabular}{|l|c|}
\hline Specification description & Numeric value \\
\hline Control signals number & 3 \\
\hline Input voltages range & $+2.7 \mathrm{~V} \ldots+5 \mathrm{~V}$ \\
\hline Output voltage & $100-160 \mathrm{~V}$ \\
\hline Operating temperature range & $-20{ }^{\circ} \mathrm{C} \ldots+45^{\circ} \mathrm{C}$ \\
\hline PCB area & $\sim 18 \mathrm{~cm}^{2}$ \\
\hline Mass & $\sim 20 \mathrm{~g}$ \\
\hline
\end{tabular}

Currently, work is being performed aimed at upgrading the amplifier driver' technical specifications. The principal trends in the device development are as follows:

- Minimisation of the size and mass characteristics;

- Improvement of the functioning reliability;

- Expansion of the operating temperature range.

\section{Conclusion}

Requirements to the mechanisms of the large antenna shape correction drives can present the developers with a number of tasks to be solved through accomplishing thorough analyses, calculations and designing. The principal tasks are development of the required force, precise positionability, and the structure' lightness and smallness. In this case development of the piezo actuators-based drives become the optimum solution.

To implement the linear drive control system, it is necessary to develop an amplifier driver that would ensure the required operating voltage and capability of multi-channel control of the piezo actuators' stroke value.

The designed amplifier driver ensures required power supply and control of piezo actuators of the developed precision linear drive presented here.

\section{Conflict of Interest}

The authors confirm that there is no conflict of interest to declare for this publication.

\section{Acknowledgement}

The work has been fulfilled within the range of implementation of the Federal Targeted Programme 'R\&D Work in the Russia Science and Technology Sector' Priority Areas for 2014 through 2020 Period'; Grant Policy Agreement No. 14.574.21.0165 dated 26.09.2017; Agreement EB 075-02-2018-1074 dated 15.11.2018. Unique identifier RFMEFI57417X0165: 'Development of wireless management system for controlling the shape of large transformed earth-based and space structures using precise drives'.

\section{References}

Bardin, V.A., \& Vasil'ev, V.A. (2014). Nano and micro movements actuators for the control system, monitoring and security. Modern Equipment and Technologies, 2-3. [In Russian]. 
International Journal of Mathematical, Engineering and Management Sciences

Vol. 5, No. 2, 319-327, 2020

https://doi.org/10.33889/IJMEMS.2020.5.2.026

Bardin, V.A., \& Vasil'ev, V.A. (2017). Combining measurement and control functions in the structure of a multilayer piezoelectric actuator of nano- and micro-motions. Measurement Techniques, 60(7), 711716.

Chi, Z., \& Xu, Q. (2014). Recent advances in the control of piezoelectric actuators. International Journal of Advanced Robotic, 11(11), 1-11. DOI: 10.5772/59099.

Choe, H., Heidbrink, S., Ziolkowski, M., Pietsch, U., Dyadkin, V., Gorfman, S., \& Chernyshov, D. (2017). A microcontroller for in situ single-crystal diffraction measurements with a PILATUS-2M detector under an alternating electric field. Journal of Applied Crystallography, 50, 975-977. doi:10.1107/S1600576717006197.

Frolov, V.Ya., Neelov, A.A., Zhiligotov, R.I., \& Bystrov, A.V. (2018). Identification of the protection parameters of the local electrical network taking into account the detuning of the inrush current. In 2018 IEEE Conference of Russian Young Researchers in Electrical and Electronic Engineering (EIConRus) (pp. 626-628). Moscow, Russia. doi:10.1109/EIConRus.2018.8317174.

Halabi, F.A., Gryshkov, O., Kuhn, A.I., Kapralova, V.M., \& Glasmacher, B. (2018). Force induced piezoelectric effect of polyvinylidene fluoride and polyvinylidene fluoride-co-trifluoroethylene nanofibrous scaffolds. International Journal of Artificial Organs, 41(11), 811-822. doi: $10.1177 / 0391398818785049$.

Heijer, M.D., Fokkema, V., Saedi A., Schakel, P., \& Rost, M.J. (2014). Improving the accuracy of walking piezo motors. Review of Scientific Instruments, 85(5), 055007. doi:https://doi.org/10.1063/1.4878624

Kabanov, S.A., Mitin, F.V., Krivushov, A.I., \& Ulybushev, E.A. (2018). Control of a Piezo Actuator to adjust the reflective surface of the space-based reflector. Russian Aeronautics, 61(4), 629-635.

Kiseleva, E., Sochava, A., \& Cherepanov, A. (2018). Telecommunication slot antenna based on a lowprofile siw structure. In 2018 IEEE International Conference on Electrical Engineering and Photonics, EExPolytech (pp. 48-51). St. Petersburg, Russia. doi:10.1109/EExPolytech.2018.8564367.

Kuptsov, V.D. (2016). Noise optimization of surface acoustic wave devices in electronic systems. In 2016 IEEE International Ultrasonics Symposium, IUS (pp. 1-4). Tours, France. doi: 10.1109/ULTSYM.2016.7728524.

Matveev, S.A., Shevtsov, I.V., Shirshov, A.D., \& Yakovenko, N.G. (2018). Wireless power supply system for flexible space antenna actuators. Russian Aeronautics, 61(4), 636-641.

Medvedev, B.M., Molodyakov, S.A., Ustinov, S.M., \& Fyodorov, S.A. (2018). Embedded systems software: trends in industry and education. In 2018 International Symposium on Consumer Technologies, ISCT (pp. 66-69). St. Petersburg, Russia. doi:10.1109/ISCE.2018.8408921.

Mitin, F., \& Krivushov, A. (2018). Application of optimal control algorithm for dc motor. application of optimal control algorithm for dc motor. Proceedings of the 29th International DAAAM Symposium (pp. 0762-0766). ISBN 978-3-902734-20-4, ISSN 1726-9679, Vienna, Austria. doi: 10.2507/29th.daaam.proceedings. 110 .

Osipov, A.A., Aleksandrov, S.E., Osipov, A.A., \& Berezenko, V.I. (2018). Development of process for fast plasma-chemical through etching of single-crystal quartz in sf6/o2 gas mixture. Russian Journal of Applied Chemistry, 91(8), 1255-1261. doi: 10.1134/S1070427218080025.

Varlamov, A.V., Lebedev, V.V., Agruzov, P.M., Ilichev, I.V., \& Shamrai, A.V. (2019). Optimal configuration of the waveguide acousto-optic TE-TM polarization mode convertor on X-cut lithium niobate substrate. Journal of Physics: Conference Series, 1236(1). doi: 10.1088/1742$6596 / 1236 / 1 / 012034$. 
Varlamov, A.V., Shamray, A.V., Lebedev, V.V., Agrusov, P.M., \& Il'ichev, I.V. (2018). Search for optimal conditions of saw excitation by lithium niobate integrated optical te-tm mode convertor. In 2018 IEEE International Conference on Electrical Engineering and Photonics, EExPolytech (pp. 172-175). St. Petersburg, Russia. doi: 10.1109/EExPolytech.2018.8564393.

Vasil'ev, A.E., Vasil'yanov, G.S., Tapia, D.F., Pereverzev, A.E., \& Nguyen, B.H. (2017). Hardware implementation of high-performance fuzzy computations based on programmable logic integrated circuits. Journal of Communications Technology and Electronics, 62(12), 1414-1426. doi:10.1134/S1064226917110183.

Vassiliev, A.E., Ivanova, T.Y., Tapia, D.F.C., \& Luong, Q.T. (2017). Microcontroller-based embedded system equipment development for research and educational support. In 2016 International Conference on Information Management and Technology, ICIMTech (pp. 219-223). Bandung, Indonesia. doi:10.1109/ICIMTech.2016.7930333.

Yenuchenko, M.S. (2018). Alternative structures of a segmented current-steering DAC. In 2018 International Symposium on Consumer Technologies, ISCT (pp. 14-17). St. Petersburg, Russia. doi:10.1109/ISCE.2018.8408905.

Yiqun, Z., Na, L., Guigeng Y., \& Wenrui, R. (2017). Dynamic analysis of the deployment for mesh reflector deployable antennas with the cable-net structure. Acta Astronautica, 131, 182-189.

Yiqun, Z., Wenrui R., Guigeng Y., \& Na L. (2016). Deployment analysis considering the cable-net tension effect for deployable antennas. Aerospace Science and Technology, 48, 193-202.

Zhengrong, C., Zongquan D., Xiaozhi Q., \& Bing L. (2014). Modeling and analysis of a large deployable antenna structure. Acta Astronautica, 95, 51-60. 